\title{
Methodological Tools for Assessing Regional Innovation Systems in the Russian Federation
}

\author{
Elena Stryabkova \\ Department of Economic Innovation and Finance \\ Belgorod State National Research University \\ Belgorod, Russia \\ Stryabkova@bsu.edu.ru
}

\begin{abstract}
The urgency of the research is in the necessity to modernize the innovation system of Russian regions and to access its effectiveness. Goal-oriented management of innovation system establishment is possible only if appropriate methodological tools are available. The role of assessing the effectiveness of regional innovation systems is becoming indisputable, and is able to identify openly weak points in the system, as well as help determine the growth poles, vector and trajectory of further transformations of this system. The paper analyzes different methodologies for assessment of regional innovation systems and proposes the author's viewpoint on this issue. Using DEA method, we carry out the analysis of innovation systems of regions in the Central Black-Earth economic region of the Russian Federation, which allows to identify weaknesses and strengths, as well as to find the poles of their further growth. It is seen that the establishment and improvement of regional innovation systems in the Russian Federation continues to evolve and should take into account such modern trends as technological connectivity of industries, digitalization and convergence of technologies, blurring and increasing transparency of regional and state boundaries.
\end{abstract}

Keywords - regional innovation system, development indicators of the regional innovation system.

\section{INTRODUCTION}

One of the most important stages in the formation and modernization of the regional innovation system (hereinafter RIS) is its assessment. Based on the dynamics of evaluation criteria, regional authorities will be able to make balanced strategic decisions regarding the development of the regional innovation system as a whole, as well as its individual growth poles. At the same time, the effectiveness of the decisions made will largely depend on the quality of the assessment methods.

In the economic literature, you can find quite a few different ways to assess the potential, stage, trajectory and vectors of RIS development, but not all of them have practical application. Moreover, the indices and ratings

\author{
Irina Ladygina \\ Department of Economic Innovation and Finance \\ Belgorod State National Research University \\ Belgorod, Russia \\ Ladygina@bsu.edu.ru
}

of the regions innovative activity, which have received recognition, also have a number of disadvantages that limit the range of their application.

We base our research on the fact that the formation of regional innovation systems occurs not only under the influence of natural factors in the development of a market economy. The instruments of the will expression of organized social communities now significantly supplement such objectively existing sources of progressive transformations as the desire of business entities to make a profit, competition, dynamic equilibrium of supply and demand. In addition, in the process of RIS formation, the influence of organized management dominates over the market forces. At the same time, for the targeted management of any system, an appropriate toolkit is needed, which has such components as the means of identifying problems, the means of setting tasks, the means of solving tasks.

The organization of an efficiently functioning RIS requires a multi-component toolkit based on different approaches already developed and new. Given the extreme urgency of the problems of the formation of innovative structures, one of the most important factors in the successful achievement of the goal is the assessment of their actual state.

\section{METHODS}

Despite the fact that the methodology for analyzing the innovation activity of individual economic entities is most developed, its application, even in a modified form, in relation to a higher system of a regional scale is impossible. A set of indicators that can give an idea of the activities of an enterprise often cannot be applied even to their group. Performance metrics scaled down to industry or locations are meaningless.

There are quite a lot of works devoted to the analysis of innovative potential. At the same time, the assessment of the regional innovative development is still the least studied, including its methodological level. 
In the analysis of works devoted to methodological approaches to the assessment of RIS, as well as the construction of basic and integral indicators of this assessment, first, I would like to note the works of F. Cook on the main driving forces of the development of the region. [1, 2]. The scientist believes that not competition, but constructive cooperation and exchange of accumulated knowledge are the key to intensive development. Due to this idea of the effective form of coexistence of individual links of regional innovation systems, the indicators of integration began to be given special importance.

A number of works by the Canadian researcher Peter James George are devoted to temporal aspects in the assessment of innovation activity. His approach is that there is a time gap, the so-called lag, between the period of investment in innovation and the period of receiving a return in the form of a finished product on the market. Often this gap becomes a significant obstacle to innovation. On the one hand, even corporations with significant financial potential are aware of the need for innovations, on the other hand, their expanded reproduction may become impossible without making a profit at every current moment of time [3].

Many authors write about the strategic importance of universities as accumulators of intellectual potential. Among them is D. Foray, who believes that the development of an innovative economy in the region requires a very close integration of science, education and production [4].

M. Fritsch presented a rather original approach in his works. The author believes that the inclusion of a subject in a well-organized field of innovative activity inevitably leads to an increase in the quality of the subject's innovative product. This view emphasizes the importance of regional growth poles and the need to include them in the overall assessment [5].

\section{MAIN PART}

The purpose of our study is to select methodological tools for assessing regional innovation systems in the Russian Federation. The objectives of the study include studying the available achievements in the field of assessing regional innovation systems; identification of the advantages and disadvantages of the already used methods of assessing RIS; search for ways to shortness the evening outs.

Based on the above mentioned approaches, a number of authors and large research teams have developed systems of specific indicators for assessing innovation systems of different regions.

Several systems have been used quite successfully to assess the innovation systems of regions of a national scale. For example, the American Science Foundation has been evaluating 33 countries for the fourth decade in terms of technological competitiveness: an indicator of national orientation, an indicator of socio-economic infrastructure, an indicator of technological infrastructure, an index of production potential and an indicator of technological state. In turn, these 5 indicators are integrated into indicators, which are used to assess the dynamics of changes in indicators over 3 years [6].

Let us look in more detail on the practice of analyzing the effectiveness of innovative activities using the Global Innovation Index (hereinafter GII) [7]. Cornell University, INSEAD Business School and the World Intellectual Property Organization (WIPO) have calculated GII since 2007, which in turn is a specialized agency of the United Nations. Individual states are the subject of assessment. The most important distinguishing feature of the GII is that its final indicator is a comparison of the results of innovation activities of countries to the costs of it. Thus, with some degree of conventionality, GII can be attributed to performance indicators. Table 1 shows the structure of the Global Innovation Index.

TABLE I. STRUCTURE OF The GLOBAL INNOVATION INDEX

\begin{tabular}{|c|c|c|}
\hline Resource indicator groups & Result indicator groups & Total indicator \\
\hline Institutions & \multirow{2}{*}{ Creative outputs } & \multirow{5}{*}{$\begin{array}{l}\text { Global Innovation Index } \\
\text { (GII) }\end{array}$} \\
\hline Infrastructure & & \\
\hline Market sophistication & \multirow{3}{*}{ Knowledge and technology outputs } & \\
\hline Business sophistication & & \\
\hline Human capital and research & & \\
\hline
\end{tabular}

It should be noted that Table 1 presents 7 groups of indicators of the highest level, and there are more than 80 basic indicators.

The main advantages of GII include the following.

1. The final indicator takes into account the results ratio of the innovative activity and the resources of such large territorial entities as individual countries. This allows the GII to be classified as an indicator of effectiveness.

2. Laconically formed groups of basic indicators, which, on the one hand, cover the multilateral aspects of innovation, and on the other hand, exclude irrelevant facts.

3. GII is calculated using weighted indicators, that is, taking into account the degree of significance of the base indicator in the final assessment.

4. GII makes it possible to compare the effectiveness of innovation activities between different states and analyze its dynamics for individual countries.

At the same time, this indicator has a number of disadvantages, from the point of view of GII applicability as a tool for assessing regional innovation systems of the Russian Federation. 
1. The GII structure includes such basic indicators and their groups, which cannot be influenced by regional authorities. For example, state institutions, including the regulatory framework, are only marginally subject to changes as a result of regional initiatives.

2. Some baseline indicators are qualitative, such as an assessment of the political environment. Such indicators are subject to the risk of subjective misstatement.

3. The Internet resource representing the GII on behalf of its developers does not provide information on the method of calculating the points assigned to each indicator and does not provide information on the weight of each indicator in the resulting.

The methodology for assessing the level of regional innovation systems development, worked out by the
Russian Institute of the National Research University "Higher School of Economics", appeared somewhat later than the GII. The first rating of the constituent entities of the Russian Federation was calculated by the team of authors based on the results of 2012 [8].

The final indicator calculated according to the methodology of the Higher School of Economics is the Russian Regional Innovation Index (hereinafter RRII). Its structure is shown in Table 2.

Table 2 does not show only groups and subgroups of basic indicators, the total number of which is more than 50.

Let's highlight the most important positive characteristics of RRII. In our opinion, these include the following:

TABLE II. STRUCTURE OF THE RUSSIAN REgIONAL INNOVATION INDEX

\begin{tabular}{|c|c|c|}
\hline $\begin{array}{l}\text { Main groups of } \\
\text { indicators }\end{array}$ & Indicator subgroups & Total \\
\hline \multirow{3}{*}{$\begin{array}{l}\text { Socio-economic } \\
\text { conditions } \\
\text { innovation }\end{array}$} & Key Macroeconomic Indicators & \multirow{16}{*}{$\begin{array}{l}\text { Russian } \\
\text { Regional } \\
\text { Innovation Index } \\
\text { (RRII) }\end{array}$} \\
\hline & Educational potential of the population & \\
\hline & Digitization potential & \\
\hline \multirow{3}{*}{$\begin{array}{l}\text { Scientific and technical } \\
\text { potential }\end{array}$} & Funding for research and development & \\
\hline & Scientific manpower & \\
\hline & Research and development performance & \\
\hline \multirow[t]{4}{*}{ Innovative activity } & $\begin{array}{l}\text { Activity in the field of technological and non-technological } \\
\text { innovations }\end{array}$ & \\
\hline & Small innovative business & \\
\hline & Costs of technological innovation & \\
\hline & Результативность инновационной деятельности & \\
\hline \multirow[t]{2}{*}{ Export activity } & Export of goods and services & \\
\hline & Export of knowledge & \\
\hline \multirow{4}{*}{$\begin{array}{l}\text { Quality of innovation } \\
\text { policy }\end{array}$} & Regulatory legal framework for innovation policy & \\
\hline & Organizational support of innovation policy & \\
\hline & Budgetary costs of science and innovation & \\
\hline & $\begin{array}{l}\text { Participation in the Federal Science, Technology and } \\
\text { Innovation Policy }\end{array}$ & \\
\hline
\end{tabular}

1.The total indicator takes into account both economic and social conditions of innovation activity in the regions of Russia.

2. The RRII team of authors has developed a system of graphical visualization of the rating assessment, which is called the "individual profile of the regional innovation system".

3. The total indicator takes into account the involvement of the subjects of the regional innovation system in national projects and programs.

4. The team of authors discloses in sufficient detail the methodological tools for calculating the final grade.

At the same time, we note several shortcomings that make it difficult to use RRII as the main tool for the formation and adjustment of the vector and trajectory of the development of regional innovation systems, as well as the search for potential growth poles in them.

1. Some indicators, the group "Quality of innovation policy" in particular, is subject to the risk of incorrect assessment. For example, the presence of an innovative development strategy (concept) does not reflect its quality in itself.

2. The values of some indicators, for example, "The number of territories of innovative development, which have been assigned special statuses in accordance with the measures of state support for scientific, scientific, technical and innovative activities provided by federal authorities" are least dependent on the administrative influence of regional authorities.

3. The algorithm for calculating the RRII evens out the contribution of the selected indicators [9] and thus does not make it possible to identify the key factors of the effectiveness of the regional innovation system and the growth pole.

Another development of Russian scientists is the Rating of innovative regions of Russia. Its developers include the Association of Innovative Regions of Russia and the Ministry of Economic Development of the Russian Federation [10]. The rating began its history in 2012. The structure of the total is presented in Table 3 .

Among the obvious positive characteristics of the Rating of innovative regions of Russia, we highlight the following:

1. The authors of the rating methodology annually cover not only the results of monitoring the current situation in the regions, but also give their recommendations on the development of innovative policy measures for each Russian region. 
2. Most of the indicators included in the rating structure are statistical data from official sources.

TABLE III. Structure Of The RAting Of InNOVAtive Regions Of Russia

\begin{tabular}{|l|l|l|}
\hline \multicolumn{1}{|c|}{ Indicator groups } & \multicolumn{1}{c|}{ Quantity of indicators } & \multicolumn{1}{c|}{ Total indicator } \\
\hline Research and development & 9 \\
\hline Innovative activity & 9 \\
\hline Socio-economic conditions for innovation & 5 \\
\hline Regional innovation activity & 6 & \\
\hline
\end{tabular}

3.The algorithm for calculating the total indicator includes a procedure for smoothing individual indicators.

In addition, like the previous methods of assessing the regional innovation system quality, the rating of innovative regions of Russia is not devoid of certain drawbacks.

1. The index is calculated by the simple average method without using weights, which makes all basic indicators equal, which is most likely somewhat different from reality.

2. A small part of the indicators is assessed either based on data from uncertain sources, or exclusively by experts from the group of rating developers.

3. The fourth group of indicators - "Innovative activity of the region" - unlike all others is formed by absolute, not

relative parameters. This approach puts large and densely populated regions in a privileged position.

Summing up the analysis of the most authoritative methods for assessing the quality and effectiveness of regional innovation systems, we note the following. Through the efforts of foreign and domestic scientists, several methods for assessing regional innovation systems have been created. Their basic indicators cover almost all areas of innovation: economic, social, political. The methods are implemented in the form of a number of ratings, which are published in open sources and can be used to assess the dynamics of the development of innovative systems of regions at the level of individual states, as well as their administrative territorial entities.

Despite the obvious progress in the toolkit for assessing regional innovation systems, attention should be paid to the possibility of its further improvement.

In our opinion, the development of methodological tools for assessing regional innovation systems should be directed along the path of optimizing the structure of basic indicators in order to identify the most significant of them. Another important characteristic of the integrated assessment model should be the availability and objectivity of information on the baseline indicators. And finally, the third condition for improving the quality of the assessment itself should be the possibility of the influence of regional authorities on its key components.

We believe that the Data Envelopment Analysis (DEA) method can be attributed to the methods for assessing the effectiveness of the functioning of institutional systems that correspond to the above tasks.
American scientists A. Charnes, W. Cooper, E. Rhodes [11], substantiated the DEA method. Its peculiarity lies in the fact that it makes it possible to assess the effectiveness of a complex socio-economic system according to several parameters. With regard to our subject of research, namely the regional innovation system, this method will allow avoiding the difficult (quite possibly impossible) stage of determining the significance of each parameter of the final assessment.

The DEA method was based on the idea of comparing efficiency in a group of manufacturing enterprises. The problem of the study was the knowledge that the already known one-dimensional models of efficiency, such as determining the coefficients of profitability, liquidity, turnover and others, do not give an idea of which company is performing better as a whole. Analysts realised that each of these metrics was important, but could not understand which one to give preference.

The core of the DEA method was the idea that for a set of homogeneous objects, be it manufacturing enterprises or regional innovation systems, it is possible to set reference objects that have the quality of the best use of available resources. Since the functional dependence between the resources used and the result obtained cannot be determined, the method assumes, on the basis of empirical observations of the values of resources and the result, to construct the boundaries of the productivity of the socio-economic system. The DEA method analyzes multiple observation points that in some way describe the performance of independent production units. Since the concept of "production unit" in this case has an abstract character, it becomes possible to study a territory where there are several variables of input and output.

Despite the fact that the DEA method is most widely used abroad [12, 13, 14, 15], Russian researchers have also successfully applied it when analyzing the effectiveness of various socio-economic systems.

E.A. Vechkinzova [16] carried out the analysis of the effectiveness of the functioning of regional innovation systems of Kazakhstan using the DEA method. For the assessment, this author used specific indicators that referred to the number of economically active population in each separate region.

The input parameters were the indicators of regional expenditures on research and development and expenditures on technological innovations. The output parameters were the volume of shipped innovative products and the number of created and used technologies and equipment. Moreover, all indicators were indexed to the prices of the initial analysis period. 
The effectiveness assessment covered the period from 2015 to 2018.

The results obtained allowed E.A. Vechkinzova, to consider the dynamics of the development of regional innovation systems, highlight the groups of regions with the most and least developed innovation systems, and also develop recommendations for the efficient use of resources in the formation of the economic policy of the regions of Kazakhstan.

S. Zemtsov and M. Kotsemir [17] carried out evaluation of the effectiveness of regional innovation systems in Russia using the DEA approach. In their work, the researchers analyzed the period 1998-2012. In order the indicators in the valuation to have a comparable form, the scientists deflated them to the 1998 level. As input parameters - resources, scientists used regional expenditures on $\mathrm{R} \& \mathrm{D}$ and the number of employed residents of the region with higher education. The output parameters are the number of patents. In this case, the indicator characterizing the amount of patents was determined by adding the weighted number of patents registered in Russia and the weighted number of international patents.

Application of DEA approach allowed S. Zemtsov and M. Kotsemir to confirm several of their hypotheses.

The subjects of our research are the regions of the Central Black Earth Economic Region, which includes the Belgorod, Voronezh, Kursk, Lipetsk, Tambov regions. In addition, in order to compare the innovation systems of these regions not only with each other, we also included the Nizhny Novgorod region in the number of analyzed regions. It is one of the leaders in the rating of the constituent entities of the Russian Federation both by the value of the Russian Regional Innovation Index and by the value of the Rating of Innovative Regions of Russia. Hypothetically, we assume that when using the DEA method, this region will be as close as possible to the reference one. The absolute leader of all ratings of regional innovation systems - the Moscow region, we did not consider as a standard because we assume an inconsistent return on the use of resources when scaling them. Moreover, since one of the types of resources in our model is the number of personnel engaged in research and development, then as a hypothetical benchmark we take a leading region not many times larger than the regions of the Central Black Earth Economic Region in terms of population.

The input parameters i.e. resources in our model of the effectiveness of the regional innovation system are: the number of personnel engaged in research and development; internal costs for research and development; the cost of fixed assets at gross book value. We have chosen these indicators for the following reasons. First, they contain the necessary information about the main factors of any production activity, not excluding innovation. Secondly, the values of these parameters are publicly available in official statistical sources. Thirdly, the values of these parameters are the most reliable, since they are formed based on obligatory reporting forms of organizations. Fourth, the regional authorities control most of these parameters.

The output parameter i.e. the result in our model is the volume of innovative goods, works, and services. In our opinion, this is the most significant resulting indicator. In addition, it also possesses such important characteristics as openness and authenticity.

In order to exclude the influence of inflation and other factors of the price environment, we have brought all the parameters that have a value measurement to the prices at the beginning of the analyzed period.

In our model, we also took into account the time lag between the period of expenditure of financial and human capital and the period of obtaining the result of this kind of investment. We took a five-year period as the lag length. It is substantiated by the three-year term of postgraduate study adopted in the Russian Federation, during which the scientist must conduct a full-fledged research and a two-year period to implement the results of the research. For example, as input data, we took the number of personnel engaged in research and development and internal expenditures on research and development for 2010, and as output data, that is, results, the volume of innovative goods, works, services for 2014 (with 5 years pass until the end of 2014).

We used the University of New England Australia program [18] as a linear programming tool required when using the DEA method. The initial data for calculations are presented in tables 4-7.

We assessed regional innovation systems based on the technical efficiency indicator. Technical efficiency in this case characterizes the region's ability to obtain the maximum volume of innovative goods, works and services from the available and used set of resources: personnel engaged in scientific research; internal expenditures for research and fixed assets. Technical efficiency can range from zero to one. At the same time, zero means a completely ineffective system, and one means the most effective among the analyzed.

The results of calculation by the DEA method of the technical efficiency of regional innovation systems, shown in Table 8, turned out to be somewhat unexpected. One of the leaders of the Russian Regional Innovation Index and the Rating of Innovative Regions of Russia, the Nizhny Novgorod Region does not have a maximum technical efficiency. In our opinion, the reason for this disagreement may be even greater economies of scale than we assumed. The resources that are involved in the innovation sphere of the Nizhny Novgorod region in absolute terms are many times higher than the similar costs of other analyzed regions. It is possible that there is a negative economy of scale in this case.

The analysis revealed two benchmark regional innovation systems among the regions of the Central Black Earth economic region: the systems of the Belgorod and Lipetsk regions. These regions should maintain the prevailing situation in 2010-2014. The ratio of the resources involved in the innovation sphere. They can increase the volume of innovative goods, works and services in the future by uniformly increasing their investments of human and financial capital. At the same time, the Belgorod and Lipetsk regions should continue to develop the infrastructural components of their regional innovation systems. 
Regional innovation systems in other regions of the Central Black Earth Economic Region turned out to be less effective. The program that we used to calculate the efficiency using the DEA method makes it possible to answer the question of which resource becomes a factor in reducing efficiency, as well as to identify the growth poles of their innovation systems.

Thus, in the Voronezh region, a very strong component of its innovation system is the personnel engaged in research and development. There are many scientists in this region, and they have a powerful research potential. Human capital involved in R\&D: Voronezh universities and institutes are the growth pole of the region. The region's scientists are almost adequately provided with funding for their research and development. In addition, there are not enough fixed assets that would allow the production of innovations be embodied in specific goods and services in the required volume.

A similar situation is developing in the Kursk region. Research institutes are also poles of growth. While capital investment is not enough.

A completely different correlation of productive forces has developed in the innovation system of the Tambov region.

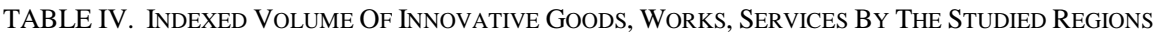

\begin{tabular}{|c|c|c|c|c|c|}
\hline \multirow{2}{*}{ Region } & \multicolumn{5}{|c|}{ Indexed volume of innovative goods, works, services, million rubles } \\
\hline & 2015 & 2016 & 2017 & 2018 & 2019 \\
\hline Belgorod region & 590052 & 737142 & 810373 & 831555 & 932390 \\
\hline Voronezh region. & 403454 & 437790 & 489878 & 543279 & 682227 \\
\hline Kursk region & 243742 & 310213 & 334443 & 361388 & 417717 \\
\hline Lipetsk region. & 528756 & 599989 & 628984 & 752967 & 694653 \\
\hline Nizhny Novgorod region. & 1177167 & 1282136 & 1313470 & 1395641 & 1676701 \\
\hline Tambov region. & 116979 & 177112 & 151689 & 175904 & 204634 \\
\hline
\end{tabular}

TABLE V. The Number Of PERsonnel Engaged In RESEARCH AND DEVELOPMENT

\begin{tabular}{|c|c|c|c|c|c|}
\hline \multirow{2}{*}{ Region } & \multicolumn{5}{|c|}{ Number of personnel engaged in research and development, people } \\
\hline & 2010 & 2011 & 2012 & 2013 & 2014 \\
\hline Belgorod region & 1189 & 1198 & 1244 & 1227 & 1373 \\
\hline Voronezh region. & 13184 & 14106 & 10799 & 10763 & 10865 \\
\hline Kursk region & 2944 & 3128 & 3018 & 3016 & 2984 \\
\hline Lipetsk region. & 323 & 326 & 365 & 379 & 443 \\
\hline Nizhny Novgorod region. & 40636 & 39902 & 40882 & 41513 & 39703 \\
\hline Tambov region. & 1665 & 1807 & 1710 & 1644 & 1625 \\
\hline
\end{tabular}

TABLE VI. INDEXED INTERNAL RESEARCH AND DEVELOPMENT COSTS

\begin{tabular}{|c|c|c|c|c|c|}
\hline \multirow{2}{*}{ Регион } & \multicolumn{5}{|c|}{ Indexed internal research and development costs, million rubles } \\
\hline & 2010 & 2011 & 2012 & 2013 & 2014 \\
\hline Belgorod region & 892 & 889 & 1116 & 1217 & 1336 \\
\hline Voronezh region. & 5287 & 4755 & 5679 & 5127 & 4736 \\
\hline Kursk region & 2129 & 1446 & 2095 & 2503 & 2586 \\
\hline Lipetsk region. & 67 & 105 & 126 & 194 & 214 \\
\hline Nizhny Novgorod region. & 31361 & 34166 & 39377 & 35941 & 43646 \\
\hline Tambov region. & 805 & 866 & 843 & 1196 & 1714 \\
\hline
\end{tabular}

TABLE VII. INDEXED VALUe OF FiXed Assets At GRoss Book VALUE

\begin{tabular}{|l|l|l|l|l|l|}
\hline \multirow{2}{*}{\multicolumn{1}{c|}{ Region }} & \multicolumn{4}{c|}{ Indexed value of fixed assets at gross book value, million rubles } \\
\cline { 2 - 6 } & \multicolumn{1}{|c|}{$\mathbf{2 0 1 0 .}$} & $\mathbf{2 0 1 1}$ & $\mathbf{2 0 1 2}$ & $\mathbf{2 0 1 3}$ & \multicolumn{1}{c|}{$\mathbf{2 0 1 4}$} \\
\hline Belgorod region & 671563 & 751582 & 814937 & 860175 & 959678 \\
\hline Voronezh region. & 788059 & 960851 & 953724 & 962015 & 920195 \\
\hline Kursk region & 435966 & 466279 & 479333 & 504300 & 795374 \\
\hline Lipetsk region. & 635096 & 676692 & 681465 & 730584 & 1775827 \\
\hline Nizhny Novgorod region. & 1578659 & 1632356 & 1722405 & 7442233 \\
\hline Tambov region. & 467691 & 491680 & 496108 & 516964 & 1776593 \\
\hline
\end{tabular}

TABLE VIII. TECHNICAL EFFICIENCY OF REgIONAL INNOVATION SYSTEMS

\begin{tabular}{|c|c|c|c|c|c|}
\hline \multirow{2}{*}{ Region } & \multicolumn{5}{|c|}{ Technical efficiency of regional innovation systems } \\
\hline & 2010 & 2011 & $\mathbf{2 0 1 2}$ & 2013 & $\mathbf{2 0 1 4}$ \\
\hline Belgorod region & 1,000 & 1,000 & 1,000 & 0,938 & 1,000 \\
\hline Voronezh region. & 0,583 & 0,465 & 0,517 & 0,548 & 0,684 \\
\hline Kursk region & 0,636 & 0,678 & 0,702 & 0,695 & 0,777 \\
\hline Lipetsk region. & 1,000 & 1,000 & 1,000 & 1,000 & 1,000 \\
\hline Nizhny Novgorod region. & 0,849 & 0,801 & 0,767 & 0,763 & 0,870 \\
\hline Tambov region. & 0,285 & 0,367 & 0,307 & 0,330 & 0,358 \\
\hline
\end{tabular}


There are enough researchers here, their development is sufficiently funded and there is a sufficient amount of fixed assets to implement the research results. The proportions between these productive forces are almost identical to the benchmark Belgorod and Lipetsk regions. Nevertheless, the efficiency of the innovation system of the Tambov region is the lowest in the Central Black Earth economic region. A possible reason for the low return on resources in this area is the underdeveloped infrastructure of innovation. In this case, it is this very infrastructure, which will be called upon to become a new pole of growth for the Tambov region.

\section{IV.CONCLUSIONS}

Having studied methodological tools for assessing regional innovation systems, we came to the following conclusions.

1. In the Russian Federation and abroad, various methods of assessing the quality, degree of development and effectiveness of regional innovation systems have been developed and have been used for a number of years. The most widespread are the Global Innovation Index developed by Cornell University, INSEAD Business School and the World Intellectual Property Organization (WIPO); Russian Regional Innovation Index, developed by the Institute of the National Research University Higher School of Economics. The rating of innovative regions of Russia, developed by the Association of innovative regions of Russia and the Ministry of Economic Development of the Russian Federation.

2. Despite the obvious great importance, the listed approaches to assessing regional innovation systems have a number of drawbacks that make it difficult to use them as the main tool for forming and adjusting the vector and trajectory of development of regional innovation systems, as well as searching for potential growth poles.

The most significant drawbacks, in our opinion, are the following:

some of the indicators on the basis of which the final index is calculated are subject to the risk of incorrect assessment; the final assessment is formed, inter alia, on the basis of an assessment of indicators that cannot be influenced by regional authorities;

the number of basic indicators is usually several dozen and the degree of their influence on the integral index is equivalent, which scatters the attention of regional authorities and does not give an opportunity to focus on the main directions.

3. In our opinion, it will be possible to level these shortcomings using the method of envelope data analysis (DEA). We came to this conclusion based on the analysis of successfully conducted research in Russia and abroad.
4. The analysis of the effectiveness of regional innovation systems of the Central Black Earth economic region of the Russian Federation carried out by the DEA method made it possible to identify their strengths and weaknesses, as well as to find the poles of their further growth.

\section{ACKNOWLEDGMENT}

The research was carried out within the framework of the state assignment of NRU BelSU FZWG-20200016 (0624-2020-0016), the topic of the project "Fundamental foundations of global territorial and industry specialization in the context of digitalization and technology convergence".

\section{REFERENCES}

[1] $\mathrm{Ph}$. Cooke, «Regional innovation systems, clusters, and the knowledge economy", Industrial and Corporate Change, 2001, Vol. 10, pp. 945-974.

[2] Ph. Cooke, "Regional innovation systems: Competitive regulation in the new Europe", Geoforum, 1992, vol. 23., pp. 365-382.

[3] P. J. George, The Emergence of Industrial America: Strategic Factors in American Economic Growth since 1870, Albany: State University of New York Press, 1982, 961 p.

[4] D. Foray, Smart specialization: opportunities and challenges for regional innovation policy. New York, Routledge, 2015, 122 p.

[5] Fritsch M, "Measuring the quality of regional innovation systems: A knowledge production function approach", International Regional Science Review, 25.1, 2002, pp. 86-101.

[6] Science and Engineering Indicators report. URL: http://www.nsf.gov/ statistics/seind06/(accessed 27.10.2020).

[7] Global Innovation Index. URL: https://www.globalinnovationindex.org/(accessed 27.10.2020).

[8] Rating of innovative development of the constituent entities of the Russian Federation. URL: https://www.hse.ru/primarydata/rir/(accessed on: 27.10.2020).

[9] G. I. Abdrakhmanova, S. V. Artemov, P. D. Bakhtin Rating of innovative development of constituent entities of the Russian Federation, Issue 6 / and others; ed. L. M. Gokhberg; Nat. issled. University Higher School of Economics, Moscow, 2020, 264 p.

[10] Rating of innovative regions of Russia. URL: http://iregions.org/reiting/rejting-innovatsionnogo-razvitiya/(accessed 27.10.2020)

[11] A. Charnes, W.W. Cooper, E. Rhodes, “Measuring the efficiency of decision making units", European Journal of Operational Research, 1978, vol. 2, pp. 429-444.

[12] Wei Yi-Ming, et al. "The assessment of vulnerability to natural disasters in China by using the DEA method", Environmental Impact Assessment Review 24.4, 2004, pp. 427-439.

[13] M. Toloo, Babak S., Soroosh Nalchigar, "A new method for ranking discovered rules from data mining by DEA", Expert Systems with Applications, 36.4, 2009, pp. 8503-8508.

[14] D. Campisi, C.A. "Roberta DEA-based method to enhance intellectual capital management', Knowledge and Process Management, 15.3, 2008, pp. 170-183.

[15] F. Deyneli, "Analysis of relationship between efficiency of justice services and salaries of judges with two-stage DEA method", European Journal of Law and Economics, 34.3, 2012, pp. 477493.

[16] E.A. Vechkinzova, "Analysis of the effectiveness of the functioning of regional innovation systems in Kazakhstan", Drukerovskiy Vestnik, 2020, 1 (33), pp. 329-340.

[17] S. Zemtsov, M. Kotsemir, "An assessment of regional innovation system efficiency in Russia: the application of the DEA approach", Scientometrics, 120.2, 2019, pp. 375-404.

[18] University of New England Australia. http://www.uq.edu.au/economics/cepa/deap.ph/(accessed 27.10.2020) 